\title{
Analysis on the Talent Training Mode of Management Science and Engineering from the Perspective of Multidisciplinary Integration
}

\author{
Delai Liu* \\ Jiangsu Yufeng Investment Guarantee Co., Ltd., Nanjing 210000, Jiangsu Province, China \\ *Corresponding author: Delai Liu, 405974229@qq.com
}

\begin{abstract}
In today's era, multidisciplinary integration is the development trend of education, which breaks the field of a single discipline and lays the foundation for the development of education. Objectively speaking, with the integration of disciplines, a new interdisciplinary is formed. This new discipline is comprehensive and systematic; in addition, it integrates knowledge, technology, and methods. It is the result of the collision of different disciplines. As an applied course, Management Science and Engineering integrates multidisciplinary knowledge, such as science and technology, information science, and mathematics. Its main purpose is to solve various problems in social and economic development. It has a long-term impact on the development of contemporary multidisciplinary education. In the new era, in order to meet the requirements of social and economic development, the teaching of Management Science and Engineering should be based on the perspective of multidisciplinary integration, combined with the current characteristics and training mode of the discipline, explore new talent training paths, and then drive the development of the whole industry.
\end{abstract}

Keywords: Multidisciplinary integration; Management Science and Engineering; Talent training

Publication date: December 2021; Online publication: December 27, 2021

\section{Introduction}

With the continuous development of social economy, human beings are facing much more problems. It is difficult to meet people's cognitive needs only by relying on a single professional knowledge. There are fuzzy boundaries between certain majors. It is necessary to integrate multidisciplinary contents to achieve a certain knowledge. At present, the integration of disciplines has become the mainstream of education. The cultivation of compound talents who are proficient in multidomain knowledge and have the spirit of scientific innovation has become the mainstream of contemporary education. At the same time, it also meets the requirements of social development. In recent years, colleges and universities in China have actively promoted the construction of new engineering disciplines, explored new paths of education, and trained compound talents based on subject integration.

\section{Development characteristics of Management Science and Engineering}

Management Science and Engineering is a discipline with a history of many years. It integrates multiple disciplines and aims to enable students to accumulate more practical experience through the learning of professional knowledge, so as to better serve the field of engineering construction. From the perspective of the traditional talent training mode, most of them focus on the cultivation of certain skills. Taking civil engineering as an example, the training of talents tends to focus on strengthening students' understanding in architectural engineering and improving students' construction skills. The cost engineering specialty has 
high requirements for students in terms of engineering measurement and pricing. At the same time, it also requires students to understand the market situation, optimize the cost scheme on this basis, and save construction costs. Taking engineering management as an example, it emphasizes on the improvement of students' on-site management skills in engineering projects. It can be appreciated that different fields have different skill requirements. With the continuous development of information technology, new technologies have been applied to the discipline of Management Science and Engineering, overturning the traditional single-discipline-teaching dilemma and playing an important role in the development of the whole industry. In this context, it is particularly necessary to explore the education path under the background of multidisciplinary integration, which can broaden the talent training path and cultivate more compound talents.

\section{Construction of the talent training mode for Management Science and Engineering from the perspective of multidisciplinary integration}

Management Science and Engineering involves a wide range of fields. In the actual management process, the concept of multidisciplinary integration should be based upon, and a new path of talent training should be explored on this basis. Secondly, in the process of formulating talent training objectives, it is essential to take into consideration of four construction points: first, the integration of the curriculum system; second, the construction of an interdisciplinary teacher team; third, the construction of an interdisciplinary platform; fourth, interdisciplinary competition organization.

\subsection{Optimize the curriculum system based on professional integration}

In the new era, teachers should break the dilemma of previous professional education based on professional integration and optimize the classroom system on this basis. Of course, talent training can also be based on two core ideas; namely, interdisciplinary and modularity. The course content should be integrated with the help of big data to form a specific course group. At the same time, in the process of constructing a curriculum system, multiple contents can also be integrated. For example, courses related to management information system (MIS), design and development can form a curriculum group, which can guide the normal production and operation of the industry. Of course, this integration is not a simple superposition of the original curriculum contents but rather a deep combination of multi-professional contents. It plays an important role in building systematic courses. At the same time, the integration of big data and production operation can also achieve the purpose of intelligent production. It is also beneficial to organically combine logistics engineering with big data, effectively predict the development of the logistics market, logistics distribution route, and arrival time with the help of big data technology, as well as further optimize the storage structure. Based on this point of view, the integration of multiple majors can also speed up the training of interdisciplinary thinking and innovative talents.

\subsection{Optimize teaching and research organizations, and strengthen scientific research}

The construction of a teaching and research team plays a key role in improving the quality of talent training. Under the new educational background, the optimization of teaching and research organization should be taken as the key work based on the construction of a high-quality teaching and research team, in order to strengthen scientific research on this basis. In this process, relevant colleges and universities should also break the original fixed teaching team with professional teaching and research departments as units, combine the development direction of Management Science and Engineering in the new era, integrate the contents of industrial engineering, logistics engineering, and engineering management, organize teacher exchange programs in relevant fields, and form a new education team. Finally, relevant teams should also 
deeply analyze the teaching design criteria of interdisciplinary courses, optimize discipline design and teaching methods on this basis, as well as create a high-quality discipline teaching system.

\subsection{Focus on interdisciplinarity and build a curriculum platform}

At present, the talent training mode based on interdisciplinarity is the mainstream of contemporary education. It does not only conform to the final development direction of education, but also infuse vigor in this kind of education. Taking cost engineering specialty as an example, three elements should be coordinated in the construction of the curriculum platform.

(1) Implement basic teaching.

In the construction of a curriculum platform, it is necessary to clarify the concept of its core curriculum and build a corresponding education platform on this basis, such as introducing courses in management, economics, and mechanics, effectively supplementing curriculum teaching content, as well as optimizing the teaching structure.

(2) Expand the depth of subject teaching.

In-depth exploration of subject content plays an important role in improving the comprehensive quality of talents. In the new era, two key points of subject education should be emphasized. First, ensure that students are clear about the future development direction through the construction of subject expansion platform. Taking housing architecture as an example, in the process of discipline setting, students should be informed about the latest information of professional development, and they should affirm the direction of their efforts in the future. Second, through professional courses, students would develop a new understanding of the major. For example, for students majoring in cost engineering, they can carry out engineering valuation and cost management through learning backbone courses, so as to further their understanding of professional contents.

(3) Expand the professional content.

Subject teaching should be based on professional development. New educational paths should be constantly explored on the basis of realizing the docking of special posts. Based on the subject content, it should be implemented from two dimensions: students' professional development and interests. Taking the project cost as an example, from the perspective of professional curriculum, multiple professional courses, such as CAD courses, can be added. At the same time, students should further expand their interests and hobbies, learn various professional-related knowledge, such as municipal engineering measurement and pricing, prefabricated structure, etc., further broaden their horizons, as well as master more professional knowledge.

(4) Strengthen practical application.

Practical application is not only an important goal of professional teaching but also of great significance for discipline development. In order to speed up the pace of talent training, teachers from relevant schools should perform well in practical teaching based on the construction of a practical platform, coordinate practical teaching contents on this basis, and further strengthen students' theoretical knowledge. At the same time, teachers should also coordinate the relationship between talent training objectives and the setting of a curriculum platform (Figure 1). 


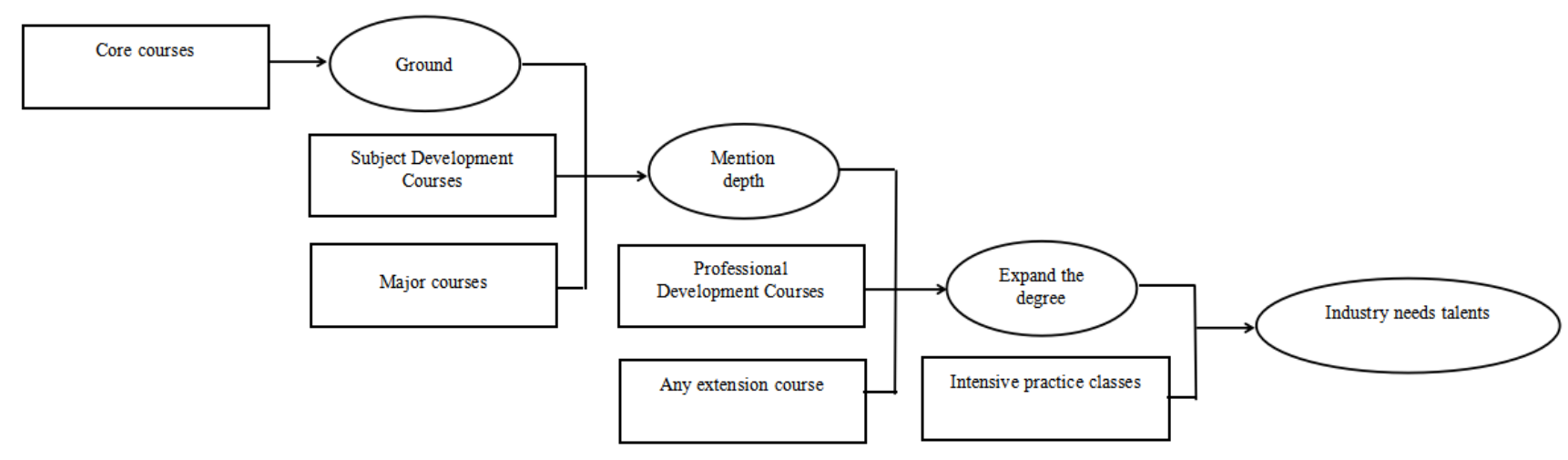

Figure 1. Logical relationship between the setting of a curriculum platform and the training objectives

\subsection{Strengthen the construction of a project team and improve the comprehensive quality}

In the new era, talent training should be based on the actual needs of enterprises. The construction of a project team should be strengthened at the same time. In this process, enterprises should also play a supportive role, introduce real projects to the campus, encourage students to carry out investigations and research in groups, as well as write research reports. For example, some enterprises regard agricultural products as important business projects. Based on the development of agricultural products, they establish an organic connection between big data technology and the logistics industry, refine the project research content on this basis, as well as promote the improvement of students' practical skills.

\section{Conclusion}

The cultivation of compound talents is an inexhaustible impetus for the development of school education and the industry. In the new era, the cultivation of professional talents should be close to compound talents, integrate professional-related knowledge into professional teaching, and further expand the professional teaching system. At the same time, based on the diversified development of students, teachers should take multiple measures from the perspectives of curriculum system construction, platform optimization, teaching and research team as well as project team construction, comprehensively improve talent quality, realize the in-depth connection between professional education and posts, as well as cultivate a number of high-quality compound talents.

\section{Disclosure statement}

The author declares that there is no conflict of interest.

\section{References}

[1] Wu M, 2019, Research on the training mode of Applied Talents in Management Science and Engineering. Overseas Chinese Garden, 2019(05): 94.

[2] Sun L, 2019, Research on talent training mode of Independent Colleges Based on Interdisciplinary Taking the Discipline of Management Science and Engineering of Tianhe University as An Example. Modern Communication, 2019(05): 44-45. 
[3] Deng S, Sun L, 2019, Research on Talent Training Mode of Management Science and Engineering Under the Background of "Transformation + Transformation" - Taking Tianhe College of Guangdong Normal University of Technology as An Example. Contemporary Educational Practice and Teaching Research, 2019(2): 96-97. 